AperTO - Archivio Istituzionale Open Access dell'Università di Torino

\title{
Multi-dimensional intelligence in smart physical objects
}

\section{This is the author's manuscript}

Original Citation:

Availability:

This version is available http://hdl.handle.net/2318/1634021

since 2020-06-29T21:11:30Z

Published version:

DOI:10.1007/s10796-017-9758-y

Terms of use:

Open Access

Anyone can freely access the full text of works made available as "Open Access". Works made available under a Creative Commons license can be used according to the terms and conditions of said license. Use of all other works requires consent of the right holder (author or publisher) if not exempted from copyright protection by the applicable law. 


\title{
Multi-dimensional intelligence in Smart Physical Objects
}

\author{
Federica Cena · Luca Console • Assunta Matassa • Ilaria Torre
}

Received: date / Accepted: date

\begin{abstract}
This paper is about characterizing intelligence in Smart Physical Objects, i.e., objects based on the tight and seamless integration of a physical and a digital counterpart. The design of these objects gives rise to new opportunities but requires taking into account a number of dimensions that contribute to smartness. In our view, supported by considerable literature on this subject, smart behavior is the result of proper combinations of several dimensions of intelligence. In the paper we analyze these dimensions, singling out different alternatives leading to different capabilities of smart objects. The contribution of the paper is to provide a framework that can guide a designer in making decisions about smartness in the physical object being designed, starting from its requisites. At the same time the framework provides an effective guide to classify and compare smart physical objects according to the type and level of smartness they exhibit.
\end{abstract}

Keywords Smart Objects · dimensions of intelligence · levels of smartness · design guidelines

\section{Introduction}

This paper is about characterizing intelligence in smart physical objects (SPO in the following), introducing different dimensions for intelligence and then showing how

F. Cena, L. Console, A. Matassa

Corso Svizzera 185, Turin, Italy

Tel.: +390116706711

Fax: +39011751603

E-mail: (cena,lconsole,matassa)@di.unito.it

I. Torre

Viale Causa 13, Genoa, Italy

Tel.: + 390103532983

Fax: +390103532948

E-mail: ilaria.torre@unige.it the dimensions can be composed to identify SPO capabilities in supporting people, singling out different levels of smartness for this type of objects.

The principle guiding us is that a smart physical object is a tight and seamless integration of a physical and a digital counterpart which augment each other to define an entity with specific features. This remark is important in characterizing "intelligence", meaning that intelligence cannot be independent of the physical nature of the object and must augment this physical dimension in the same way as the physical dimension is the handle to support intelligent behavior enabled by the digital dimension. This means that an SPO is, first of all, a physical object with its physical nature, properties and functions but, at the same time and at an abstract level, it can be seen as an "Intelligent Agent" according to classical definitions in the literature, i.e. "a computer system that is situated in some environment, capable of autonomous action in this environment in order to meet its design objectives" (Wooldridge \& Jennings, 1995). With respect to this definition, the physicality of an SPO introduces features such as the affordances of the object, i.e., its actionable properties, and the perceived affordances (Gibson, 1977; Norman, 2002), which have to be integrated in the design of the agent.

In the paper we will not make any specific assumption about the physical layer, in the sense that the object can be of any type, material, shape, etc. and we do not consider the design of such a layer. We focus on the digital part of an SPO and on the integration of the digital and the physical part. The digital part may include different types of electronic components (such as those managing communication, micro-controller, sensors and actuators), necessary to support interaction and exchange with the physical world. 
Based on the characterizations of intelligence in the literature, the paper presents our definition of SPO, claiming that smartness in this class of systems involves several dimensions to be taken into account. The paper introduces these dimensions, provides some instruments for designing and analyzing each dimension and shows that several alternatives are available in each one of them. It then discusses the consequences of different choices on the capability of an SPO to support users and interact with them.

The contribution of the paper is twofold. On the one hand, it provides a framework for the conceptual design of an SPO. A designer (by designer we intend the computer scientist and the interaction designer focusing on the digital dimension) can exploit the dimensions we single out to make decisions about the type of intelligence to be embedded in the SPO to be developed, starting from its requisites. On the other hand, the framework can be used as a reference guide for comparing and evaluating the levels and types of smartness of different SPOs.

The paper is organized as follows. Section 2 presents some background work in the literature. Section 3 introduces our definition of SPO and provides an overview of the framework with a running example that will be used in the rest of the paper. Section 4 presents our decomposition of intelligence into abilities and analyses different dimensions within each ability. Section 5 recomposes the abilities to characterize different levels of smartness in an SPO. Section 6 exemplifies this discussion using the running example of the smart chair. Sections 7 and 8 provide some evaluation of our approach, involving respectively smart objects we developed and objects developed by other researchers. Section 9 provides some final considerations.

\section{Background}

The notion of intelligence is controversial. In computer science it is usually defined, in relation to intelligent agents, as the ability to have intelligent behavior. In this work, we refer to the general definition of an intelligent agent as a computer system that is situated in some environment and that is capable of autonomous action in this environment in order to meet its design objectives (Wooldridge \& Jennings, 1995). According to this definition, an agent should at least show: reactivity, i.e., the ability to perceive the external environment and take appropriate measures in response to perceptions; proactivity, i.e., the ability to take initiatives based on its own evaluation of relevant conditions; social ability, i.e., the ability to communicate with other agents. The ability to learn is another fundamental component of intelligence (Russell et al., 2003), even though some researchers consider it as a specific property of some agents and not an essential feature of intelligent agents (Franklin \& Graesser, 1996).

Cognitive sciences and education offer a number of useful insights about intelligence and smartness which we exploit in our framework. As concerns the definition of intelligence, a principle that we borrow is its multidimensional nature expressed for example in the CattellHorn-Carroll theory of intelligence and its extensions (McGrew, 2005) and in the theory of multiple intelligences (Gardner, 1983) In these studies, smartness is described as the perceived quality of being effective in a given situation. Smartness is the preferred term used in ubiquitous computing to refer to agents with some ability to perform some intelligent task (Ma et al., 2005; Fortino et al., 2012). Thus, smart seems more focused on reaching specific goals in a given context.

The term Smart Object (SO) has been often used according to this interpretation of smartness, applied to physical things (Vasseur \& Dunkels, 2010; Kortuem et al., 2010; Lopez et al., 2011). For example (Kortuem et al., 2010), smart objects are autonomous physical/ digital objects augmented with sensing, processing, and networking capabilities. They sense, log and interpret what occurs around them, act on their own, communicate with each other and exchange information with people. This is strictly related to the notion of Ambient Intelligence, which refers to predominantly electronic solutions that allow environments to be sensitive, adaptive, and responsive to the presence of people (Mukherjee et al., 2009). Fortino et al. (Fortino et al., 2012) define smart objects as networked software agents that can perform specific tasks for a user and possessing a degree of intelligence that permits them to perform parts of their tasks autonomously and to interact with their environment in a useful manner. Other definitions focus on communication. A smart object contains a digital layer useful to support communication to a plethora of sensors and actuators embedded in it. This allows the object to establish communication processes and this differentiates it from a traditional embedded system (Vasseur \& Dunkels, 2010). Our decision of using the term SPO (Smart Physical Object) instead of the more common SO (Smart Object) is to emphasize the role of the physical part of the object, which affects both interaction and reasoning. Our framework is thus focused on objects where the physical and digital components are integrated.

In recent years, with the development of the Internet of Things (Li et al., 2015), several classifications of smart objects have been provided. One of the most popular approaches classifies smart objects according 
to a service discovery perspective (Fortino et al., 2014; Lackovic \& Trunfio, 2014). A classification model based on smart objects capabilities is proposed in (Perez Hernandez \& Reiff-Marganiec, 2014), which also provides a survey of previous classification models. The authors distinguish between core and optional capabilities. Basically, the core capabilities plus the hardware-driven optional capabilities address the concept of a networked object, while the other optional capabilities address the features of an intelligent object, sharing features with our approach. Similarly, a recent classification (Nguyen, 2015) provides a multilayered taxonomy of smart objects that comprises ten dimensions structured along the architectural layers of IoT stacks. Specifically, the first two levels concern capabilities related to identification and networking, the third level concerns features from embedded systems such as sensing and actuating capabilities, the fourth is about awareness of itself and the environment and the fifth level is about social-readiness, self-management. The paper provides also some interaction design techniques, showing the importance of defining new interaction paradigms when designing smart objects. Concerning cognitive capabilities, the framework in (Wu et al., 2014) is one of the most closely related to our approach. It describes five cognitive tasks (perception-action cycle, massive data analytics, semantic derivation and knowledge discovery, intelligent decision-making, and on-demand service provisioning) and provides guidelines on enabling techniques involved in the cognitive tasks.

The limit of these classifications and design principles is that they are focused on interaction or on cognition, while our contribution is to identify guidelines to take into account both aspects in order to build smart objects that are both intelligent and effective to interact with people and the other objects. With respect to this concept a related issue concerns the measurement of smartness of devices. Recent studies tried to assess the smartness of building, appliances, etc., using the criterion of how much help the object provides to the user (Ozkul \& El Zarka, 2013). Our framework does not use quantitative measures to assess smartness however this could be a useful integration of our guidelines.

\section{The framework: an overview}

\subsection{Definitions and terminology}

In this section we provide a definition of terms and concepts used in our framework. As we noticed in the introduction we are interested in objects with a dual physical-digital nature. Moreover we are interested in objects with which we interact in our everyday life in order to accomplish some tasks. Thus, we adopt the following definition of SPO.

A Smart Physical Object (SPO) is a real world object having the capability to support people in their activities, interacting and managing social relations with them, the context and possibly other smart objects. Such capabilities are based on the ability to reason about knowledge and data.

The term smart in an SPO is used to characterize the ability of the object to apply its intelligence to support people in their activities. Moreover, an SPO is an interactive system (i.e., it interacts with people and possibly with other objects and the environment) and provides some sort of service to users integrated into its core functions (e.g., supporting in related tasks, providing recommendations, making decisions, etc.). Some examples are: fitness devices with health monitoring functions and social abilities, smart bicycles which monitor pollution levels and provide navigation support for more healthy and less congested roads, smart tools for workspaces with interacting functions to support workers to configure and use them and providing advice for safety and security.

In order to decompose the concept of smartness and to identify different dimensions and granularity levels, the framework adopts a pragmatic approach, singling out five abilities that in our approach can concur to define different forms and levels of smartness. Such abilities are split in two groups:

- Cognitive abilities: i) knowledge management, i.e., the ability to maintain knowledge ii) reasoning, i.e., the ability to make inferences; iii) learning, i.e. the ability to learn from experience.

- Interaction abilities: iv) object-object interaction (OOI); v) human-object interaction (HOI).

\subsection{Goals of the framework}

The main aim of the framework is to provide guidelines to the designer of an SPO, showing that the design can be decomposed along the abilities mentioned above and that a number of alternatives can be considered for each one of them, discussing the meaning of the different choices and the consequences they have on the level of smartness of the resulting SPO. The framework takes the point of view of a designer with a set of requirements about the functionalists of the object and with the need to evaluate which are the benefits of some choices in terms of smartness of the SPO with respect to the effort to achieve such smartness. The effort is not defined in terms of costs but in terms of needs (that is, what is needed in order to achieve different levels of 
smartness). This decomposition will allow the designer to make informed choices on several design alternatives.

The framework can be also used to classify existing SPOs and to compare them: in this case the decomposition into abilities provides a set of classification criteria to perform structured comparisons of SPOs.

Engineering design process is often described as a five-step process (Dieter et al., 2013). In Figure 1 we show the use of our framework within a design process aimed to build a new smart physical object. We can observe that it can support each step of the process, since it can help to:

- identify dimensions of analysis,

- look for and compare similar SPO,

- identify design choices,

- match requirements and design choices,

- compare and evaluate design choices,

- identify the features that distinguish the SPO with respect other SPOs.

\subsection{Theoretical instruments to analyze the abilities}

To analyze different dimensions within each ability we use a number of instruments from the literature.

In the analysis of cognitive abilities we will consider four ontological categories, borrowed from model-based reasoning (Chittaro et al., 1993), where multiple dimensions are taken into account in order to model physical objects:

i) Structure: concerns the physical/digital structure of an object (e.g., the chair could be made of leather, and embed sensors).

ii) Teleology: concerns the goals an object is designed to have (e.g., if the object is a smart chair, one of its goals could be to monitor the user's health state; this object will be used as a running example in the following).

iii) Function: concerns the functions that the object can perform to reach its goals, "what the object can do" (e.g., the chair can measure blood pressure).

iv) Behavior: concerns the way a specific function is executed, i.e., the actions that the object performs when a function is activated ("how to do": e.g., the chair may measure blood pressure by inflating micro cells).

Moreover we will consider the reasoning patterns that are commonly adopted in the formal characterization of reasoning processes: (i) deductive, (ii) abductive, (iii) inductive, (iv) analogical, (v) common sense. Deduction is the standard form of logical inference; abduction allows to explain observations while induction allows to generalize from examples. Analogy enables an object to make inference on a specific situation based on similarities between the situation and other previously encountered ones (e.g., case-based reasoning). Common-sense includes various forms of non monotonic inference, e.g., drawing conclusions by default or in absence of evidence to the contrary. All these patterns may have to deal with uncertainty (in the data and in the inference process).

As regards interaction abilities, we will exploit the Activity Theory (see for example (Nardi, 1996)), claiming that an activity cannot be understood without taking into account the role that an object plays in everyday practice. Considering activities instead of simple tasks implies considering the goals of a person when interacting with an object in a given context and what the task means to her. Currently this is a fundamental concept in HCI research (Moran, 2005).

In order to classify the kind of interactions between humans and objects, we borrow the terms Moran used in his grammar for describing the user interface (Moran, 1981). We use these terms to describe different types and levels of interaction of a SPO with a human (but possibly also with other SPOs).

- Task level identifies the functions that an object offers and the consequent tasks that a user or other SPOs can accomplish by exploiting such functions and capabilities.

- Syntactic level defines the linguistic model that a user has to adopt to communicate with an artifact; thus, this level defines the linguistic and interaction model exposed by SPOs to make them interacting, exploiting their physical and digital properties.

- Semantic level enriches the syntax level with the meanings of the commands and of the rules for interacting with an artifact, thus with an SPO. New meanings can arise from the interaction.

- Interaction level determines the forms of relationships that can occur between a user, an artifact and the environment; in our view it corresponds to the ways adopted by an SPO for establishing relationships with humans and objects in the surroundings which influence all of them. It is the highest level of interaction because it supports complex relationships of influence between SPOs, users and other SPOs.

Moran's classification is used to analyze different design levels of a user interface, while in our adaptation it is used to describe different types and levels of interaction abilities existing in an SPO. Also other works have adopted these terms to represent the level of interaction, such as (Wang \& Yu, 2016) which add a further level, named apobetic, intended as a positive feeling 


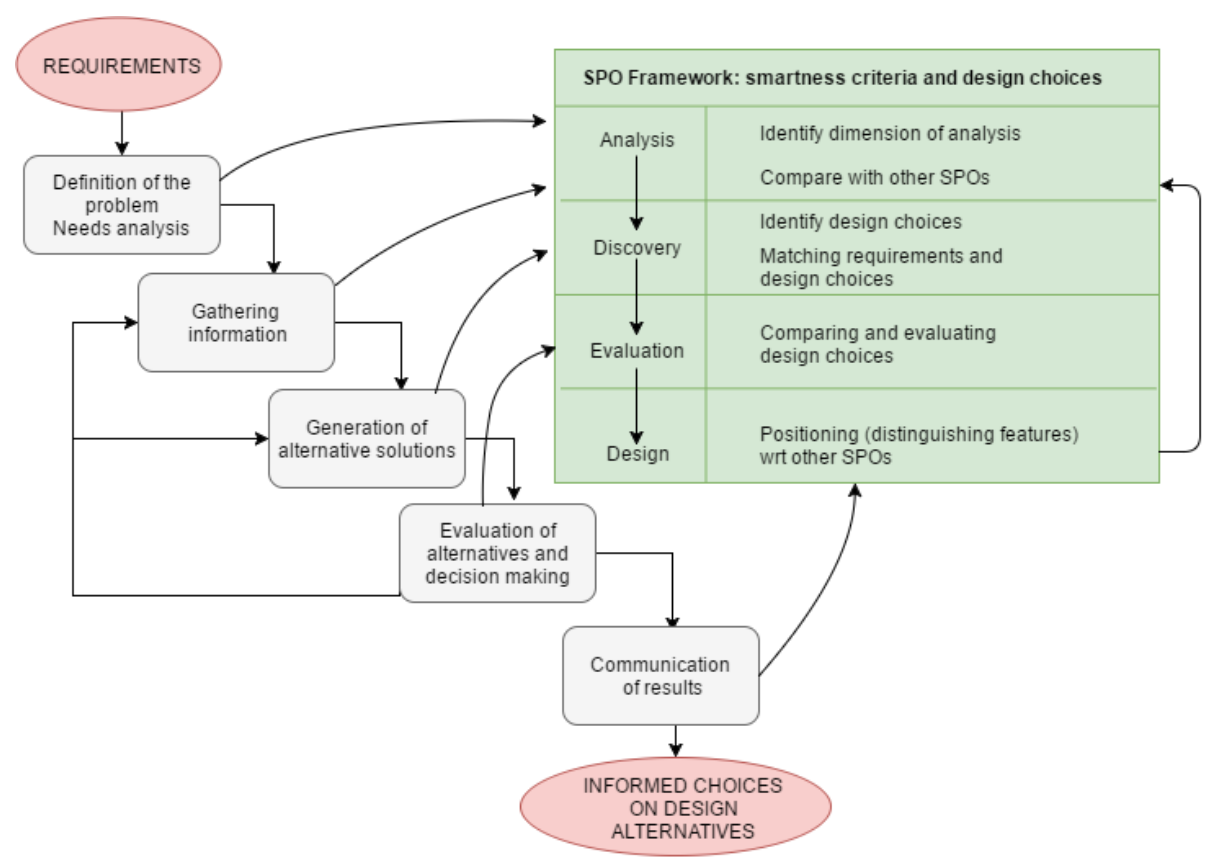

Fig. 1 Using the framework in the design process of a SPO.

coming from an interaction that achieves the expected results.

\subsection{Running example}

In this section we introduce an example that we will use as a running one throughout the paper. Let us suppose that we want to design a smart chair to be used in an office environment. The following are examples of requisites that might have to be considered:

- The chair monitors the user and supports her in her work. Requirements on this item could vary from monitoring the physical and ergonomic user position alerting in case of bad positions, to monitoring and interpreting user's actions and hypothesizing her goals.

- The chair communicates with and coordinates with other objects. For example, it might coordinate with the lighting systems (to set appropriate light given the user behavior or goals) or it might coordinate with the user personal computer.

- The chair is proactive suggesting the user appropriate behavior (e.g., staining up every couple of hours).

Different types of chairs could be designed, selecting requisites from above. From a simple chair that monitors the user position providing alerts to a complex chair that is able to capture the user's goals and that coordinates the other office devices, given these goals, the context and user's preferences.

Some smart chair prototypes described in the literature present examples of user position monitoring and classification aimed to correct the user posture (e.g., (Martins et al., 2013)) or providing support to users (e.g., (Ma et al., 2016)).

In the following we will analyze how different chairs can be designed, starting from requisites like the ones above and decomposing the design choices according to the set of abilities discussed above. In this way we will map requisites to design choices and we will discuss the consequences of such choices in terms of the level of smartness (and sophistication) of the chair being designed.

\section{A decomposition into abilities}

In this section we analyze separately the abilities singled out above and we discuss the dimensions that have to be considered for each ability. For each one we exploit the example of the smart chair for discussing how the designer can match requisites to these dimensions and alternatives and thus the resulting level of smartness of the designed SPO. In Figure 2 we provide a simplified schema of the framework representing the dimensions of analysis, the main design choices and the interrelation of design choices. 


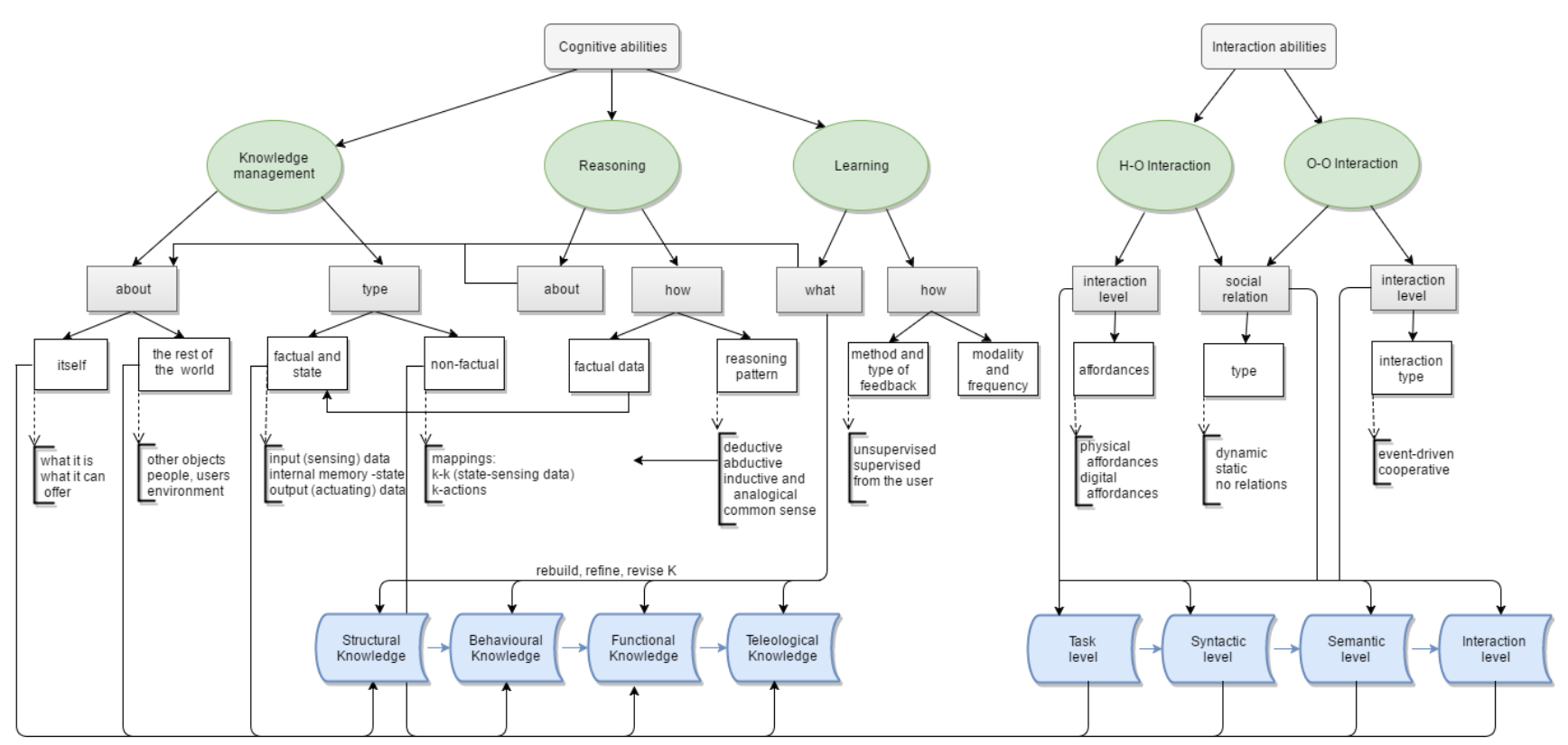

Fig. 2 Schema of the framework for SPO design.

\subsection{Knowledge management ability}

Maintaining knowledge is a fundamental ability of an intelligent entity. For the sake of our classification, we distinguish two separate issues: (i) which aspects of the world have to be modeled (that we call the dimensions of knowledge) and (ii) the types of knowledge to be considered.

Dimensions of knowledge An SPO, being an augmented physical object, may maintain different kinds of knowledge concerning its twofold nature. This makes it aware about such a dual nature, about its physical and digital properties and about the (physical and/or digital) services it can offer to users. Moreover, it may maintain different kinds of knowledge about the world around it. In order to provide an overall characterization of the kinds of knowledge an SPO can maintain, we define a matrix of dimensions. We consider the four ontological categories defined in Section 3.3 (structural, teleological, functional, behavioral knowledge), and then we further distinguish between (i) knowledge about itself and (ii) knowledge about the rest of the world.

Knowledge about itself: the object may have knowledge about its structural properties (shape, materials but also sensors, actuators), about the goals for which it was designed, the functions it can offer to achieve these goals, and about how it behaves when the functions are activated (behavior).

Knowledge about the rest of the world: the object may have knowledge about the physical and digital world around it, i.e., other objects, people and the envi- ronment. Also in this case we distinguish among structural properties of the world, teleological knowledge about the goals that other objects and people may pursue, knowledge about the functions they can offer to achieve them and knowledge about the behavior of other objects and people.

The dimensions for knowledge management are summarized by the matrix in Table 1 .

Types of knowledge A further distinction that we define concerning the knowledge management ability is between factual and non-factual knowledge.

Factual knowledge and state. An SPO may maintain information which can be related to either its physical or digital counterpart (or both). This includes: (i) information coming from the sensing subsystem or factual information about itself or other objects or people it interacted with (a sort of working memory), (ii) information about the actions it can perform (actuation system) towards the user. Memory is also associated to the notion of "state" which in turn can be a physical or digital state in which an object can be. An SPO can be in different physical states (e.g., an object may be physically deformed when touched) and this may or may not have a digital counterpart keeping track of the state. An SPO can also have a digital state which is not directly the counterpart of a physical state; for example, keeping track of different modes in which the SPO can be. The state can then influence the reasoning process of the SPO and its interaction with people and other objects.

Non-factual knowledge. This includes knowledge that relates (i) the internal state, and the information com- 
Table 1 Dimensions of Knowledge in an SPO

\begin{tabular}{|l|l|l|}
\hline Category & About itself & About the rest of the world \\
\hline $\begin{array}{l}\text { Structural } \\
\text { knowledge }\end{array}$ & $\begin{array}{l}\text { Knowledge about its physical/digital structure, } \\
\text { e.g., the material it is made of, the handles it } \\
\text { offers to users, its sensors/actuators, the digital } \\
\text { interfaces it offers. }\end{array}$ & $\begin{array}{l}\text { Knowledge about the context around the object, } \\
\text { e.g., structure of the environment, other objects } \\
\text { and people, interfaces that other objects offer } \\
\text { (physical and digital). }\end{array}$ \\
\hline $\begin{array}{l}\text { Teleological } \\
\text { knowledge }\end{array}$ & $\begin{array}{l}\text { Its own goals (private or public): systemic goals } \\
\text { (e.g., sustainability, well being, saving energy,...) } \\
\text { and object's specific goals. }\end{array}$ & $\begin{array}{l}\text { Goals of other objects and people: objective goals } \\
\text { that the other objects or people expose; subjec- } \\
\text { tive view of the goals of other. }\end{array}$ \\
\hline $\begin{array}{l}\text { Functional } \\
\text { knowledge }\end{array}$ & $\begin{array}{l}\text { Functions that the object can offer: related to } \\
\text { goals; activated by interactions on the physi- } \\
\text { cal/digital handles and lead to activation of other } \\
\text { ones; simple or composite (plans). }\end{array}$ & $\begin{array}{l}\text { Functions that other objects may offer, such as } \\
\text { exposed APIs: what functions are; how can func- } \\
\text { tions be activated; who can provide them. }\end{array}$ \\
\hline $\begin{array}{l}\text { Bhe way an object operates when a function is } \\
\text { knowledge }\end{array}$ & $\begin{array}{l}\text { Information about the behavior of people and ob- } \\
\text { jects. }\end{array}$ \\
\hline
\end{tabular}

ing from the sensing system, to (ii) the actions (decisions) to be made by the objects. At a conceptual level we can regard it as a set of mappings that can be used by the SPO to decide how it can support the user. Such mappings can involve all the dimensions of knowledge mentioned above: structural, teleological, functional and behavioral about itself or the rest of the world, concerning the digital or physical aspects of the SPO.

SPO smartness The ontological categories mentioned above correspond to different levels of awareness an SPO can have about itself and/or about the world around it. Although it is difficult to relate them strongly to different levels of smartness, some considerations are worthwhile. One could argue that the sequence teleologicalfunctional-behavioral-structural mirrors a decreasing degree of awareness in object intelligence. Behavioral knowledge without functional one corresponds to knowing how to act without knowing what one can actually do: we can thus argue that an SPO having only behavioral knowledge is less aware (and less smart) than one having functional knowledge. It must be noticed, however, that having functional knowledge without behavioral one may correspond to create a potential without the ability to actually perform. Similar considerations can be made for comparing the functional with the teleological level. Teleological knowledge corresponds to the highest level of consciousness, but at the same time teleology without function can result in purely speculative abilities.

These considerations apply to both factual and nonfactual knowledge. For the latter the analysis is more complex since mapping may involve different dimensions of knowledge. However we can draw a scale ranging from relations that map structural information about itself and the rest of the word to structural actions performed by the chair to relations that map elegiacal information about the object and the rest of the world (goals of the user and other objects) to the SPO own goals and thus to the support that can be provided to the user.

Running example. Let us consider the example of the smart chair. According to different types of requisites, the designer can decide which type of knowledge should be represented and the level of each one. Table 2 contains examples of knowledge that the designer of the chair could represent, according to some of the dimensions discussed above.

Examples of mappings are the following:

- At the simplest level, the chair may adopt mapping from the user's structural properties to structural changes in the chair itself (e.g., change backseat inclination when the user's weight is above a given threshold).

- More complex mappings may take into account behavioral information about the user (e.g., the fact that she keeps the lights on when she leaves the office) and information about the environment (e.g., lighting conditions), mapping them to changes in the chair functions and changes to the environment itself (e.g., changing the lighting conditions).

- An even more sophisticated mapping may correlate user's goals to the goals and setting of the chair and the environment (e.g, the fact that the user has the delivery of a document scheduled on her calendar may induce the chair to set a comfortable environment, avoiding distractions and adapting automatically the position to the user movements).

The selection of the types of knowledge is guided by the requisites. Thus, a first task for the designer is to map requisites to the types of knowledge discussed in this section. The dimensions above provide guidelines to this process, highlighting the effects in terms of level of awareness and smartness of the SPO being designed.

The aim is to make designers pay attention to a set of aspects concerning knowledge and their implications 
Table 2 Dimensions of Knowledge in a smart chair: some examples

\begin{tabular}{|l|l|l|}
\hline Category & About itself & About the rest of the world \\
\hline $\begin{array}{l}\text { Structural } \\
\text { knowledge }\end{array}$ & $\begin{array}{l}\text { knowledge about its being made of wood, with } \\
\text { cloth seat and back, about its sensors (e.g., pres- } \\
\text { sure) and actuators (e.g., vibration). }\end{array}$ & $\begin{array}{l}\text { Knowledge about the environment (e.g., the } \\
\text { lightening conditions) and knowledge about the } \\
\text { user (e.g., her weight) acquired by sensors. }\end{array}$ \\
\hline $\begin{array}{l}\text { Teleological } \\
\text { knowledge }\end{array}$ & $\begin{array}{l}\text { Meing unobtrusive wrt other objects ensuring a } \\
\text { comfortable sitting and a safe position to user. }\end{array}$ \\
\hline $\begin{array}{l}\text { Functional } \\
\text { knowledge }\end{array}$ & $\begin{array}{l}\text { Gathering data about user behavior (e.g., pos- } \\
\text { ture). }\end{array}$ & $\begin{array}{l}\text { Driving other objects to stimulate a user reaction } \\
\text { (e.g., turn off the light). }\end{array}$ \\
\hline $\begin{array}{l}\text { Behavioral } \\
\text { knowledge }\end{array}$ & $\begin{array}{l}\text { The way sensor data are collected; reactions to } \\
\text { sensor data. }\end{array}$ & $\begin{array}{l}\text { The way to interact with other objects (e.g., with } \\
\text { the lightening system). }\end{array}$ \\
\hline
\end{tabular}

from a conceptual point of view which can improve the definition of design specifications.

\subsection{Reasoning ability.}

The capabilities of an SPO depend heavily on the ability to reason on knowledge. Reasoning abilities can be classified according to multiple dimensions: i) the type(s) of knowledge involved in the reasoning process; ii) the factual information involved; iii) the reasoning patterns.

Type of Knowledge: reasoning may involve one (or more) types of knowledge discussed in Sec. 4.1; i.e. knowledge about itself or about the rest of the world (or both), and may regard the structural, teleological, functional, or behavioral knowledge (or a combination of them).

Facts involved: reasoning may involve different pieces of factual information: (i) input (sensing) data, (ii) the object internal memory or state, (iii) output (actuating) data.

Reasoning pattern: reasoning may involve one or more of the patterns mentioned in Section 3.3.

Depending on the requisites, the designer can make the appropriate choices along the three dimensions above. The choices along the first two dimensions depend also on the choices made on the dimensions concerning knowledge management. The choice among the reasoning patterns depends on the tasks to be implemented in the chair: deduction is the basic pattern needed to make inference from input data and to select the action/service to be provided. Abduction can be adopted whenever data have to be interpreted or explained (e.g., to hypothesize user's goals or to explain the environment context). Non monotonic forms of inference are useful whenever data may be incomplete or knowledge is partially available. Analogical forms of reasoning may be useful if the chair is required to operate forms of casebased problem solving (performing with a user in the same way as with similar users). Induction is especially useful in learning process (see below).
SPO smartness. The sophistication of SPO reasoning capabilities is influenced by (i) the number and types of knowledge that are involved and (ii) the type and number of reasoning patterns that are adopted. As regards the former the same consideration made for the knowledge management dimension hold also in this case. As regards the latter we can argue that flexibility, i.e. the possibility of adopting multiple reasoning patterns contribute to the perception of a smarter SPO. As regards the patterns, it is difficult to rank them, even though one can argue that non-monotonic pattern are more sophisticated are closer to human common-sense reasoning that the basic patterns such as deduction.

Running example. Consider a smart chair that has to provide an alert to the user since her position could be dangerous for her back. This involves reasoning abilities for recognizing the current user position, reasoning abilities to decide after how much time such a position may be dangerous and reasoning abilities to decide how to alert the user. A combination of reasoning patterns can be used. For example abductive reasoning, such as fuzzy classifiers, for the first reasoning task, while the second and third could exploit deductive reasoning to draw inferences from available knowledge. Knowledge should include both factual knowledge (e.g., knowledge extracted from pressure sensors on the chair) and nonfactual knowledge (e.g., mappings that relate a position and its duration to the risks for health, which can further involve different dimensions of knowledge).

\subsection{Learning ability}

Learning from previous experience is a fundamental ingredient of intelligence (Russell et al., 2003). This is also true for SPOs which can learn from the way people (and possibly other objects) interact (physically and/or digitally) with them, or they can learn from how the they people and the environment react to their actions. Learning is a reasoning activity and in this sense could be characterized as a (set of) special cases(s) according to the dimensions discussed in the previous section. 
However, learning is specific in the sense that not only does it exploits a knowledge base but it builds/refines/ revises it as well.

Learning tasks are related to dimensions such as: (i) the types of input data, including data from the physical and digital dimensions; (ii) the output, in terms of type of knowledge acquired/revised/refined (Sec. 4.1); (iii) the type of feedback the SPO can exploit in the learning task, distinguishing supervised learning (trained with classification examples), unsupervised learning and reinforcement learning (using a trial-and-error approach); (iv) the methods and algorithms that the SPO adopts (decision trees, clustering, Bayesian approaches, rulebased approaches, neural networks, etc.); (v) the modality and frequency of the learning task (periodical running, event-based, trigger-based). Combinations along these dimensions lead to different capabilities.

The ability to learn from experience may or may be not included in the requisites for designing an SPO. The choice along the dimensions above depends on the specific requisites, the choices made in the knowledge management and interaction abilities and the context in which the SPO operates. This choice has then an impact on the reasoning patterns to be implemented.

SPO smartness. It is worth noting that the ability to learn has a very strong impact on the level of smartness perceived by a human interacting with the object. An SPO which can learn complex forms of knowledge (e.g., teleological knowledge about itself or people) dynamically from experience in a fast way, with limited need of supervision, would obtain the highest ranking in smartness by humans' judgement.

Running example. Consider a smart chair that has to learn when to activate the heating control. The chair is able to monitor several variables, such as its own temperature, the room temperature, dampness, day and time, but it has no knowledge about which values of these variables are correlated with the preference of the user for heating the chair. The chair can track the user actions. All the actions of switching on and off the heating control can be used as feedback to learn the input conditions. After a training period, the chair could be able to know how to manage heating for the user's comfort.

\subsection{Human - Object interaction (HOI)}

SPOs represent a special class of objects because of their intermixed physical and digital nature. As objects, SPOs maintain their original aspect and function but in the meantime they incorporate intelligent behavior. Depending on the kind of knowledge they manage and the kind of reasoning they are able to perform, they can adapt their interaction modalities, even though they maintain the same shape and core function.

Borrowed from HCI literature, mapping (Norman, 2002 ) is the process by which users are able to understand and predict the flow of interaction with an object. Furthermore, natural mapping and meaningful interaction (Norman, 2002) are used when the effect of a performed action is naturally predictable. There is a plethora of factors enabling a natural mapping (Gibson, 1977; Moran, 1981; Norman, 2002), among them a relevant role is covered by affordance (Gibson, 1977; Norman, 2002; Chemero, 2003; Matassa, 2015). This is a concept used to define the capability of an object to make evident to users which actions can be performed with it, inducing the right interaction between users and objects, according to the context of use. Combined with the previous knowledge of the user and the environmental context, affordances should predict the interaction model with the object, creating a mental path that describes how the action that a user wants to perform could be achieved and its effects.

SPOs make the definition of an interaction model more complex since, while they maintain a traditional aspect, their capabilities are enhanced and enriched by the intelligence embedded into them. Thus, designing an SPO requires to consider their intermixed physical and digital nature and then to identify new kinds of affordances and interaction handles (Nielsen, 1995; Matassa \& Simeoni, 2015).

According to (Garde-Perik et al., 2013), we can analyze this issue as an input-output problem. An SPO is the enhancement of a physical object characterized by a shape and some interaction handles; the digital enhancement should respect the object traditional function and interaction model (Chi et al., 2007) and avoid any conflicts between them. Users may have to learn unfamiliar input-output relations quickly to exploit the capabilities offered them by SPOs and in order to avoid cognitive dissonance (Festinger, 1962) and the creation of a "gulf of interaction" (Norman, 2002) as a figurative distance between what an object suggests to do to the user and the results derived from this interaction (Norman, 2002).

In this view, affordances in SPOs are more than the actions that are possible with the object and the consequences of those actions (Matassa, 2015). They act as a complex system due to the combination of what actions are possible with the physical properties and the object teleological knowledge, which concerns the object's goals. Thus, by combining these two parts, affordances in SPOs put together interaction abilities and cognitive abilities, defining a novel unity of the behav- 
ioral act, specifying the goal-directed action. Thus the novel notion of interaction is based on the cooperation of the whole spectrum of capabilities of the SPO.

SPO smartness. At the simplest level an SPO can offer a pre-defined set of affordances corresponding to a task level interaction with the user (see further discussion in Section 4.6). More sophisticated and dynamic forms of interaction (at the interaction or semantic level) may involve offering dynamic affordances depending on the relation with the user and the context. The capability of objects of being aware of the interaction with humans involves the ability of being aware about social context. This is a form of social intelligence (Thorndike, 1920) that has been defined as the ability to be aware of the behavior of each individual and possibly of the social relations and interactions among the individuals (e.g., group detection, friendship prediction, situation reasoning) (Guo et al., 2013). A social smart object should be able to recognize a social relation in the environment and to adapt its actions to it, providing different services to people in relation to the social context (Console \& et al., 2013).

Running example A smart chair that changes its form on the basis of the user's posture, that alerts her to stand up and move when she is sit still for a long time, might affect the user perception of such an object and might evoke dissonant feelings in users if no proper affordances are provided.

\subsection{Object-Object Interaction (OOI) ability}

The ability of machines to interact is often referred to as Machine to Machine (M2M) interaction (Husain et al., 2014). SPOs enhance machine-to-machine interaction, involving different types of knowledge and enabling several forms of interaction.

The type of interaction and the relations among nodes are relevant dimensions to be taken into account. Relations among SPOs may be defined as static relations, based on predefined models of interaction among SPOs, and dynamic when SPOs are able to manage relations and are autonomous to create them. This can be seen as progressive level of smartness.

Simpler models of interactions among SPOs can be event-driven. For example, the event-driven approach can be used to describe SPOs behaviour when they are able to sense and reply to some contextual events and to respond by changing their status. In this model SPOs interact among each other according to causal relations that regulate the real world and people (Terada \& Tsukamoto, 2005).

Examples of more complex dynamic relations are offered by the Multi-Agent System (MAS) paradigm.
Typically MAS research is referred to software agents, but the agents in a multi-agent systems could equally well be robots, humans or smart physical objects. A MAS (Wooldridge, 2009) is defined as a computerised system composed of multiple interacting communicating intelligent agents acting within an environment. A MAS can be used to solve problems that are difficult or impossible for an individual agent to solve. Relationships among agents are typically dynamic: agents can cooperate and work together, be antagonists or have various combinations of these two types of behavior. This requires complex protocols for ruling interaction, e.g. based on game-theoretic techniques (Myerson, 1991).

SPO smartness. SPOs that are able to manage dynamic interactions with other objects show a high level of smartness. In analogy with the human evolution from "homo sapiens" to "homo agens" used in economic and sociological studies, Atzori et al. (Atzori et al., 2014) observe a similar evolutionary path in object intelligence. Starting from a "res sapiens" (an intelligent standalone object) moving to a "res agens" (an object connected with other objects by the programmer, communicating by means of protocols), we arrive to a "res socialis" (an object that is part of and acts in a social community of objects, with a sort of "social consciousness" and the capability of being proactive in defining new relationships).

Running example. Consider a smart chair that maintains relations with a lighting system. This relation may be static with a pre-defined interaction pattern (switching the light on at a given time) or dynamic (negotiating the optimal lighting, given an analysis of the user goals and contextual situations).

\subsection{Interaction levels}

The classification mentioned at the end of Section 3.3 can be usefully exploited to analyze the interaction levels in HOI and OOI.

This classification leads to define the type of relational abilities of an SPO. While the task level corresponds to a "static" form of interaction, in which an SPO interacts just to accomplish a native task, moving to the Syntactic and Semantic level supports more flexible and "dynamic" forms of interaction and the latter, in particular, supports dealing with the meaning of the tasks performed by the SPO. Finally the interaction level supports the establishment of a deep relation where objects (and humans) influence their behaviour according to their interrelation, coherently with the Activity Theory principles. 
Table 3 Levels of interaction managed by a smart chair

\begin{tabular}{|l|l|l|l|}
\hline Level & Action & Knowledge & Activity \\
\hline Task & Tracking and monitoring of user data. & Functional and structural knowledge. & Mono-directional \\
\hline Syntactic & $\begin{array}{l}\text { Interaction with ambient lights via a set } \\
\text { of commands. }\end{array}$ & $\begin{array}{l}\text { Functional, structural knowledge of it- } \\
\text { self and the other object. }\end{array}$ & Bidirectional \\
\hline Semantic & $\begin{array}{l}\text { Interaction and collaboration with am- } \\
\text { bient lights in response to the environ- } \\
\text { ment or the user's state. }\end{array}$ & $\begin{array}{l}\text { Functional, structural of itself and the } \\
\text { other object, teleological knowledge. }\end{array}$ & Reactive \\
\hline Interaction & $\begin{array}{l}\text { Interaction, collaboration, negotiation } \\
\text { with other SPOs to respond to user's } \\
\text { needs. }\end{array}$ & All types of knowledge. & Proactive \\
\hline
\end{tabular}

These levels can guide the designer in choosing the appropriate level for the object being designed, given the available requirements. The requirements can in fact be analyzed having the abilities discussed in the subsections above as guidelines, singling out the objects and people the SPO has to interact with and the type and level of interaction with each one of them.

Let us consider the example of the smart chair. Table 3 provides examples of different interaction levels.

\subsection{Classification of levels of smartness}

Once smartness has been decomposed in the abilities discussed in the previous section, we can use such dimensions to characterize SPOs levels of smartness. Table 4 sums up with a graphical representation the levels of smartness for each ability. An SPO can thus be classified according to each line of the table and this can provide a framework for designing and comparing SPOs. .

\section{Recomposing abilities for SPO design}

In this section we analyze how the dimensions in the previous sections can be put together to provide adaptive support to users with different levels of smartness. Specifically we use the example of recommendation as a general case of interactive support where the SPO suggests a specific action, service, or information to the user choosing among those that it can offer, using (possibly) the most suitable interaction modality among those available and deciding when to provide this functionality (when required by the user or when evaluated as necessary by the SPO itself).

The following is intended as a sort of checklist of dimensions to take into account for the design of an SPO which is required to provide recommendations to users as an enhanced (smart) functionality bound with its normal use.
1) Managing knowledge about itself. In order to provide support an SPO should maintain:

1.1 a model about itself

1.2 a model about what it can offer to the user in terms of services, interaction, information.

The SPO may maintain structural information about itself and its physical and digital properties (this makes SPOs very different from software agents). In addition, it may maintain information about the functions it can offer, about its behavior and at the highest level of sophistication about its goals.

2) Managing knowledge about the rest of the world. In order to provide recommendation, a SPO must have first of all:

2.1 a model of the user with her preferences, needs and her state (what is she doing, what did she do, what actions is she performing on the SPO, etc). Modeling a user can be done at different levels. At the lowest level it may involve structural information (e.g., the user's height or weight). A more sophisticated model may include functional (and behavioral) information such as the user's habits or preferred activities. An even higher level of sophistication may include teleological information about the user's goals. Different complexity levels in user modeling can support different forms of adaptation and thus different levels of smartness perceived by the user.

2.2 Information about the context in which the SPO operates and about other SPOs are further dimensions that can be taken into account, depending on the specific SPO. The simplest representations involve structural information only (e.g., physical information or the list of other SPOs) while progressively more sophisticated representations may involve information about the functions, behaviors and goals of other objects.

3) Maintaining social relations. An SPO can maintain a graph of social relations with other SPOs and with people. Different levels of smartenss range from the maintenance of static links with others to the ability of modifying the relations as a result of the interac- 
Table 4 Levels of smartness

\begin{tabular}{|c|c|c|c|c|c|c|}
\hline Abilities* & $\begin{array}{l}\text { Knowledge } \\
\text { manage- } \\
\text { ment }\end{array}$ & Reasoning & $\begin{array}{l}\text { Learning } \\
\text { (what) }\end{array}$ & $\begin{array}{l}\text { Learning } \\
\text { (how) }\end{array}$ & HOI-OOI & $\begin{array}{l}\text { Social rela- } \\
\text { tions }\end{array}$ \\
\hline Dimensions & $\begin{array}{l}\text { teleological } \\
\text { functional } \\
\text { behavioral } \\
\text { structural } \\
\text { (about itself / } \\
\text { about the rest } \\
\text { of the world) }\end{array}$ & $\begin{array}{l}\text { common-sense } \\
\text { [inductive, } \\
\text { abductive, } \\
\text { deductive] } \\
\text { no reasoning }\end{array}$ & $\begin{array}{l}\text { teleological } \\
\text { functional } \\
\text { behavioral } \\
\text { structural }\end{array}$ & $\begin{array}{l}\text { unsupervised } \\
\text { supervised } \\
\text { from the user } \\
\text { no learning }\end{array}$ & $\begin{array}{l}\text { interaction } \\
\text { semantic } \\
\text { syntactic } \\
\text { task }\end{array}$ & $\begin{array}{l}\text { dynamic } \\
\text { static } \\
\text { no relations }\end{array}$ \\
\hline $\begin{array}{l}\text { Levels } \\
\text { of } \\
\text { smartness }\end{array}$ & $\begin{array}{l}\text { decreasing } \\
\text { from } \\
\text { teleological to } \\
\text { structural }\end{array}$ & $\begin{array}{l}\text { decreasing } \\
\text { order but } \\
\text { increasing } \\
\text { according to } \\
\text { the number of } \\
\text { patterns that } \\
\text { are combined }\end{array}$ & $\begin{array}{l}\text { decreasing } \\
\text { from } \\
\text { teleological to } \\
\text { structural }\end{array}$ & $\begin{array}{l}\text { decreasing } \\
\text { from } \\
\text { unsupervised } \\
\text { to no learning }\end{array}$ & $\begin{array}{l}\text { decreasing } \\
\text { from } \\
\text { interaction to } \\
\text { task }\end{array}$ & $\begin{array}{l}\text { decreasing } \\
\text { from dynamic } \\
\text { to no relations }\end{array}$ \\
\hline
\end{tabular}

*Notice that Abilities in column 1 have been slightly rearranged to make more clear their influence on the SPOs smartness. Learning is split in two parts; HOI and OOI have been grouped accordingly to Section 4.6, and the Social relation ability has been taken out of both HOI and OOI.

tion. This is connected to the ability to cooperate with others to provide adaptive support.

4) Adaptation. Adaptive recommendation involves choosing what is offered to the user, when and how. Compared to a software agent, an SPO can perform adaptation at more levels, often connected one to each other.

4.1 It can change its structure.

4.2 It can modify its affordances.

4.3 It can adapt its function or behavior and thus the services it offers.

4.4 The highest form of intelligent adaptation corresponds to adapting its own goals to the goals of the user. Interaction is important in adaptive recommender systems, both as a way of getting information about the user and context and as a way of putting adaptive behavior into practice. The physical nature of an SPO has a particular role in this interaction as users expect intuitive forms of interaction. By knowing itself, its user and the context, the SPO can select a proper interface, in terms of mediator between itself and the rest of the world, to provide adaptive support. Intelligent forms of adaptation require sophisticated forms of interaction (from syntactic to semantic and interaction).

5) Reasoning for adaptation. For the sake of simplicity let us decompose the task into subtasks:

5.1 recognizing the user's features (e.g., needs, preferences), This task can range from a simple form of data gathering to complex forms of abductive reasoning to analyze the user's behavior or to interpret her needs and goals.

5.2 selecting the items to be provided to the user

\section{3 presenting them in an adapted way}

The second and third tasks can be performed deductively relating user preferences to the features to be tailored and to the most appropriate presentation. Adaptation can be also implemented as a form of analogical reasoning, by providing the user with something that other similar users appreciated in previous interactions.

6) Reasoning for cooperative adaptive support. In some cases an SPO may need to cooperate with other SPOs. At the simplest level, the interactions can be simple and isolated (e.g., requests for performing a task). At the highest level an SPO may be able to participate (or coordinate) forms of cooperative planning in order to provide the best service to the user.

7) Learning. The ability to learn makes a difference in how the smartness of an SPO is perceived. In an SPO, learning may regard different aspects. At the simplest level it may be a form of caching information for subsequent retrieval. At a more sophisticated level it may involve the revision of the SPO's knowledge base concerning the others (e.g., learning about the users, updating their models) or itself - learning about its structure or relations with others, or learning new functions it can perform or new behaviors to accomplish a function or, at the highest level, learning new goals it can achieve.

\section{Case study: designing and comparing different smart chairs}

The aim of this section is to show how to apply our framework to design and compare different SPOs, using 
as an example the smart chair whose potential requisites were discussed in section 3.4.

\subsection{Case 1: high level of smartness}

We start by considering a chair with high level of smartness according to our classification and whose goal is to support the user in her work and well-being; to accomplish these goals, it maintains different types of knowledge:

(a) About itself: structural (its components such as shape, material, etc.), teleological (its goals, i.e. to support the user in performing her tasks and thus reaching her goals), functional and behavioral (its capability to vibrate, make a sound, or communicate with other SPOs). (b) About the rest of the world: Concerning the user: structural (e.g., the user's weight), teleological (including long term goals, such as losing weight, or short term goals, such as submitting a paper on time), functional or behavioral (her habits, such as working at night) and functional. Concerning the context; regarding other SPOs (e.g., the light system, the heating system). Also in this case knowledge may regard different types (e.g., the goals of the heating device, the structure of the light system).

To gather data about the user and context the SPO can exploit its sensors, or interact (HOI) directly with the user (asking for them) or exchange data with other SPOs in the office (OOI).

The smart chair can then reason on this knowledge in order to be able to perform an adaptive behavior. The adaptive support to the user is performed through the set of subtasks described in the previous section:

(i) Recognizing the user's specific needs: it can exploit its sensors, or exploit knowledge and observations to abduce information about the user (e.g., hypothesize user's goals from the observation of her behavior). In performing this task it can exploit all types of knowledge mentioned above, i.e., knowledge about its sensor to interpret measurements on the user; teleological knowledge to hypothesize user's goals (possibly exploiting also knowledge about the context).

(ii) Selecting what to provide: the chair can exploit its knowledge about the user's goals, features and the current context to decide the service to be offered. At a structural level, it can change its shape to suggest safer and more comfortable positions; furthermore it can reason on the user's goals to adapt its own goals (deciding to support a working position, given the user's imminent deadline). Consequently, it can adapt its functions, e.g., changing the user's parameters it has to monitor according to the current user activity, or it can change its behavior, contacting other SPOs in the environment, e.g., involving other SPOs to manage lighting, re-direction of telephone calls, etc.

(iii) Adapting presentation: for example, the chair may decide to vibrate or to interact with other SPOs so as to switch on the light in order to wake up the user (deductive reasoning, planning, $\mathrm{HOI}$ at the semantic and interaction levels). Affordances of the physical/digital interaction with the user are fundamental since enable the user to make correct assumptions about how to interact with the SPO and what to expect from the interaction.

(iv) Learning: the chair could be able to learn from the experience. For example, it can learn it has to move under the desk when the user goes out of her office, or it could learn that the user is annoyed by phone calls when she works and thus it has to interact with the user's smartphone to redirect them.

The chair described above would reach the highest level of smartness in the classification in Table 4. Let us now analyze the consequences of changing the levels of smartness along the dimensions singled out in the paper.

\subsection{Case 2: lower levels of smartness}

A chair with less consciousness about itself (item (a) above) may fail to interpret data from the user. Thus the interaction can only be syntactic and this reduces the ability of the chair to interpret user needs (item (i) above). If the chair does not know its own goals or functions, it can support the user (item (ii) above) in a less flexible way and it will have almost no opportunity to interpret user's feedback and exploit it for learning.

Limiting knowledge about the user (item (b) above) impacts the chair's ability on all the tasks ((i)-(iv)) above. Missing teleological knowledge about the user reduces the interaction level and has a strong impact on the chair's ability to perform all the tasks above. The chair cannot anticipate user's needs; it can still adapt its support but interpreting user's action at a syntactic level. Similarly, missing knowledge about user's functions further reduces the chair's performance to a reaction to user's behavior. As in the case above, reducing the level of knowledge strongly impacts the learning ability since it reduces the possibility of interpreting user's feedback which can be perceived as purely syntactic actions.

Similar considerations holds for knowledge about the context (item (c)) above. In this case the analysis is particularly interesting as regards the interaction with other SPOs which can range from a purely syntactic level (in case the chair has only knowledge about 
their structure and behavior) to an interaction level, in case the chair knows about the goals of other SPOs and can negotiate with them about the functions they can activate to cooperate with the chair in its task to support the user.

In an extreme case, a chair which can deal with structural knowledge only can perform limited forms of adaptation of its structure (e.g., the rigidity) to user's structural features (e.g., her weight). The chair and interact only syntactically and can be hardly be perceived as an intelligent one.

A chair which cannot learn about the user's habits will not be able to anticipate them by performing adaptation as soon as it recognizes a recurrent behavior. Learning requires the ability to interpret the user's feedback and use them to revise some parts of the model maintained by the SPO. Depending on the involved dimensions, we can classify different forms of learning. A shallow form corresponds to learning how to behave, without actually revising neither the model about itself nor the user model. Deeper forms of learning involve revising the model of the user (starting from the structural one and going up to the teleological one). Introspective learning corresponds to revising the model about itself. For example, the chair may learn that at a given time the user should be warned to stand up (without actually worrying about the reason why). A more intelligent chair may learn that the user needs to make a call every day at a given time and thus she needs to be warned (learning functional knowledge). An even smarter chair might learn that the goal of the user is to communicate some results of her work every day at a given time (learning teleological knowledge) and thus it could plan how to support this task.

A chair which cannot maintain social relations with other SPOs cannot cooperate with them. The awareness about these relations depends on the knowledge the SPO has about itself and about other objects. A chair without teleological knowledge about other SPOs cannot produce plans to cooperate with them. A chair without functional knowledge about other SPOs can have difficulties in asking them to co-operate on a specific task.

The examples above show in a concrete way the mutual interaction among cognitive and interaction abilities, i.e., that different levels of smartness in object's cognitive abilities can affect its interaction capabilities and the other way around. Moreover, they also clarify that different levels of smartness along different dimensions can be considered when designing an SPO. In doing that there is clearly a trade-off to be taken into account. Increasing levels of smartness mean increasing complexity in both modeling knowledge and reasoning processes and this means (i) complexity in the design process and (ii) need for computational power in the SPOs (or accessible to the SPOs). In the case of the chair, intelligence has to be embedded in the chair or the chair should have access to this power via some connection to computing resources. Balancing levels of smartness and complexity is indeed a main issue in the design of SPOs and the fact that they are physical entities makes the problem more critical than in the case of software agents.

\section{Applying the framework to prototypes we developed}

In this section we analyze some examples of SPOs using our framework. We present three research projects developed by the authors which show how to use the framework to guide the design process. These prototypes are examples of SPOs with different levels of smartness.

eCube (Cena et al., 2014), is a physical wooden cube with a tangible interface which supports users in selfreporting their mood. It allows the collection of emotional states in an amusing, simple and appealing way. Moreover it provides adaptive reminders according to the user preferences.

WantEat (Console \& et al., 2013) is a network of smart everyday objects (gastronomy products such as food, wine, etc.) that are able to provide information about the territory from which they come and about their social network made of other objects (similar products) and people (producers, sellers, etc.). The objects become smart when the user gets in touch with them using a mobile app and they are able to create new social relations with other objects and users and to provide adaptive content selection to user.

iCushion is our last prototype, still under development in collaboration with Telecom Italia. It is a smart pillow to detect sedentary habits of users by means of pressure sensors and to provide adaptive visual and tactile feedback to the user when she has been sitting too much (vibrating or making a smart textile to change its color, plus providing a textual report on pc or smartphone). The system is adaptive since it changes the feedback modality according to user preferences. which is able to reason on users goals in order to provide them different functionality.

In Figure 3 we classify our SPOs according to Table 4 (Levels of smartness). It should be clear that the aim of the framework is not to provide a global score of smartness, but using the concept of level of smartness as a design and classification criterion. Therefore, 


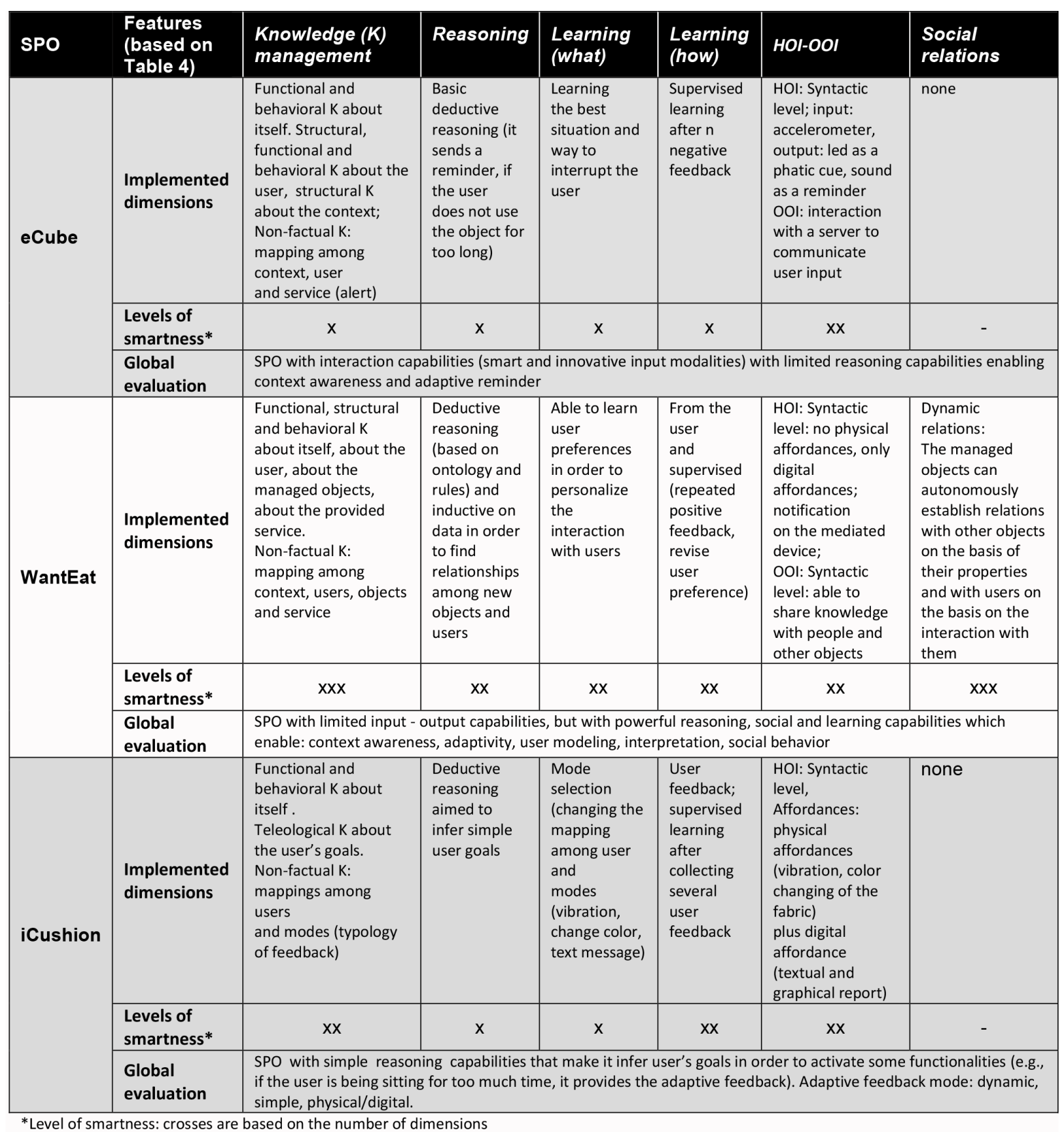

Fig. 3 Dimensions and levels of smartness in developed SPOs

crosses, within the 'Level of smartness' row, are simply intuitive visual representations of smartness level for each dimension, based on Table 4.

\section{Evaluation of the framework}

In order to make a preliminary evaluation of our approach, we adopted a qualitative assessment methodology consisting in structured open interviews to 4 researchers from different Departments of our Universities, all working in the IoT field and with several years of experience.

\section{Objective and subjects}

- Two of the subjects are researchers who recently designed smart objects.

They were required to analyze their system with respect to the framework. The aim of this evaluation was to collect feedback specifically focused on the use of the framework to design new SPOs.

- The other two subjects are researches with expertise in IoT personal devices. 
They were required to analyze 2 wearable smart objects (commercial products). The aim of this evaluation was to collect feedback about the use of the framework to classify and compare SPOs. By asking the same subjects to analyze the same two SPOs, we aimed to get feedback about:

- how different designers use the framework to analyze the same objects,

- how the same designer evaluates two different objects, so to get feedbacks about the ability of the framework to compare SPOs.

Methodology. The subjects of both the groups were preliminary asked to:

- read the paper,

- analyze each SPO with respect to the framework (subjects in the first group analyzed the SPO they developed; the others the commercial SPOs),

- fill in a table with the results of their analysis.

We then interviewed each subject using the table they filled in as a track for the interview and updating it, if necessary, during the interview. The tables of the interviews are reported in Appendix A.

Interview. Each interview was structured in two parts. In the first part subjects had to discuss how they decomposed/analyzed the SPO with respect to the dimensions of the framework. In the second part subjects had to provide an overall comment about the framework from the design point of view and from the classification point of view, structured into pros and cons. However, it is worth noting that the design process involves also the analysis of similar and competitor SPOs, as outlined in Figure 1, thus the use of the framework for design purposes includes also the use of the framework for classification.

Table 5 reports the answers concerning the overall comments about the framework (numbers in cells represent each subject, identified as subject.group: 1.1, $1.2,2.1,2.2)$. Appendix A reports the whole interviews.

Findings. In summary the feedback from this preliminary evaluation was quite positive and encourages us to continue our work in the development and formalization of the approach we presented in this paper. The evaluation provided also useful feedback about aspects that could be improved. As concerns the design perspective, researches remarked that the use of our framework would have been very useful to guide them during the design process. All of them pointed out that they did not take into account some of the dimensions of our framework during their work, while it would have been useful to (1) speed up the analysis and (2) consider di- mensions and alternatives they did not have in mind when designing their systems.

As concerns the classification perspective, researches pointed out the utility of the framework to perform systematic comparisons.

\section{Conclusion and discussion}

In this paper we presented a framework for the design and the classification of smart real-world objects based on a multi-dimensional characterization of intelligence. We used the term SPO (Smart Physical Object) instead of the most common SO (Smart Object) to emphasize their physical nature integrated with a digital intelligent counterpart. Moreover, in our characterization, a SPO is a real world object having the capability to support people in their activities, interacting and managing social relations with them, the context and possibly other smart objects. Such capabilities are based on the ability to reason about knowledge and data.

First, we identified five different abilities that may concur to define different forms of intelligence and we decomposed them in dimensions of design and analysis. Then we showed how these dimensions can be composed to characterize SPO capabilities and thus different levels of smartness in supporting users.

The Internet of Things provides a natural environment in which SPOs can deploy their abilities. After more than a decade of development (Gubbi et al., 2013; Whitmore et al., 2015; Atzori et al., 2010), the IoT has experimented several forms of smartness, by enhancing the objects or the network (Holler et al., 2014; Atzori et al., 2014), and is now going toward the so called Cognitive IoT where "general objects can not only see, hear, and smell the physical world for themselves, but also learn, think, and understand physical and social worlds by themselves" (Wu et al., 2014). Physical objects maintain their own structure, behavior, functions and goals, but are equipped with a digital layer which provides them with different types of intelligence.

In the paper we have underlined that the ability to learn from experience improves significantly the level of smartness of an object. This ability, however, can also generate worries regarding the adoption of smart physical object-based paradigms, as demonstrated by debates on the risks that may arise from the adoption of intelligent agents (Russell et al., 2015).

The contribution of the paper is to provide a framework that can guide a designer in making decisions about choices that may impact on the utility and smartness of the physical object being designed, starting from its requisites. At the same time the framework aims 
Table 5 Overall qualitative evaluation of the framework.

\begin{tabular}{|c|c|c|}
\hline & Pros & Cons \\
\hline Design & $\begin{array}{l}\text { 1.1 Using the approach was fairly easy } \\
\text { and valuable to understand where I could } \\
\text { make choices and provide insights about } \\
\text { improvements on some of the dimensions. } \\
1.2 \text { Using the framework when designing my } \\
\text { smart object would have been interesting, } \\
\text { especially for analyzing the requirements. }\end{array}$ & $\begin{array}{l}1.1 \text { Nothing specifically. The framework } \\
\text { is complex but the graph was very } \\
\text { useful to identify rapidly all the } \\
\text { alternatives. } \\
1.2 \text { It was not immediate using the approach } \\
\text { and understanding its philosophy. }\end{array}$ \\
\hline Classification & $\begin{array}{l}2.1 \text { Very useful to make you analyze the } \\
\text { object in depth and compare with other objects. } \\
\text { It forces you to analyze everything in detail. } \\
2.2 \text { A useful guideline to compare smart objects. } \\
\text { It can help when you want to make a systematic } \\
\text { comparison. }\end{array}$ & $\begin{array}{l}2.1 \text { I had some difficulties distinguishing } \\
\text { between behavioral and functional } \mathrm{K} \text {. } \\
2.2 \text { It often happens that you cannot } \\
\text { find all the information you need about } \\
\text { the object you are analyzing, therefore the } \\
\text { comparison has to be done at a higher level. }\end{array}$ \\
\hline
\end{tabular}

to be an effective guide to classify and compare smart physical objects according to the type and level of smartness they exhibit. The framework is especially targeted to designers, with specific regard to computer scientist and interaction designer focusing on the digital dimension of the smart object.

Even though other design frameworks and classifications have been provided with regard to smart objects, our work is focused on a specific kind of smart objects with interactive and supporting capabilities that make necessary a deep integration among interaction modalities, physical/digital affordances and the embedded intelligence.

In conclusion, with this work we have contributed to provide a guideline about the relevant dimensions that a designer has to be aware of when defining the specifications for a new SPO.

\section{References}

[Dieter et al., 2013]Dieter, G., E., and Schmidt, L., C. (2013) Engineering design, Vol 3. McGraw-Hill New York.

[Atzori et al., 2010]Atzori, L., Antonio I., Morabito, G. (2010). The internet of things: A survey. Computer networks, 54(15):2787-2805.

[Atzori et al., 2014] Atzori, L., Antonio, I., Morabito, G. (2014). From "smart objects" to "social objects": The next evolutionary step of the internet of things. Communications Magazine, IEEE, $52(1): 97-105$.

[Cena et al., 2014]Cena, F., Lombardi,I., Rapp, A., Sarzotti, F. (2014). Self-Monitoring of Emotions: a Novel Personal Informatics Solution for an Enhanced Self-Reporting. In Proc. of the Workshop on Emotions and Personality in Personalized Services, at UMAP14.
[Chemero, 2003]Chemero, A. (2003). An outline of a theory of affordances. Ecological psychology, 15(2):181-195.

[Chi et al., 2007]Chi, P.Y.P., Chen, J.H., Liu, S. Y., Chu, H.H. (2007). Designing Smart Living ObjectsEnhancing vs. Distracting Traditional HumanObject Interaction. In Human-Computer Interaction. Interaction Platforms and Techniques, pages 788-797. Springer.

[Chittaro et al., 1993]Chittaro, L., Guida, G., Tasso, C., Toppano, E. (1993). Functional and teleological knowledge in the multimodeling approach for reasoning about physical systems: a case study in diagnosis. IEEE Transactions on Systems, Man, and Cybernetics, 23(6):1718-1751.

[Console \& et al., 2013]Console, L., et al. (2013). Interacting with social networks of intelligent things and people in the world of gastronomy. ACM TIST, $3(1): 4: 1-38$.

[Festinger, 1962]Festinger, L. (1962). A theory of cognitive dissonance, volume 2. Stanford university press.

[Fortino et al., 2012]Fortino, G., Guerrieri, A., Russo, W., (2012). Agent-oriented smart objects development. In Gao, L., W. Shen, J-P.A.. Barthes, J. Luo, J. Yong, W. Li, \& W. Li (eds), Proc. of the International Conference on Computer Supported Cooperative Work in Design CSCWD, pages 907-912. IEEE.

[Fortino et al., 2014]Fortino, G., Rovella, A., Russo, W., Savaglio, C.(2014). On the Classification of Cyberphysical Smart Objects in the Internet of Things. In Proc. of the International Workshop on Networks of Cooperating Objects for Smart Cities at UBICITEC 2014, volume 1156, pages 76-84.

[Franklin \& Graesser, 1996]Franklin, S., Graesser, A. (1996). Is it an Agent, or just a Program? A Taxonomy for Autonomous Agents. In Proc. of the International Workshop on Agent Theories, Archi- 
tectures, and Languages, Springer Berlin Heidelberg, pages 21-35.

[Garde-Perik et al., 2013] Garde-Perik, E. V. D., Offermans, S., Boerdonk, K. V., Lenssen, K. M., Hoven, E. V. D. (2013). An Analysis of Input-output Relations in Interaction with Smart Tangible Objects. ACM Trans. Int.. Intell. Syst., 3(2):9:1-9:20.

[Gardner, 1983]Gardner, H. (1983). Frames of Mind: The Theory of Multiple Intelligences. Basic Books, New York, NY.

[Gibson, 1977]Gibson, J. (1997) The theory of affordances. Perceiving, acting, and knowing: Toward an ecological psychology, pages 67-82.

[Gubbi et al., 2013]Gubbi, J., Buyya, R., Marusic, S., Palaniswami, M. (2013). Internet of Things (IoT): A vision, architectural elements, and future directions. Future Generation Computer Systems, 29(7):1645-1660.

[Guo et al., 2013]Guo, B., Zhang, D., Yu, Z., Liang, Y., Wang, Z., Zhou, X. (2013). From the internet of things to embedded intelligence. WWW, 16(4):399-420.

[Holler et al., 2014]Holler, J., Tsiatsis, V., Mulligan, C., Avesand, S., Karnouskos, S., Boyle, D. (2014). From Machine-to-machine to the Internet of Things: Introduction to a New Age of Intelligence. Academic Press.

[Husain et al., 2014]Husain, S., Prasad, A., Kunz, A., Papageorgiou, A., Song, J. (2014). Recent Trends in Standards Related to the Internet of Things and Machine-to-Machine Communications. J. Inform. and Commun. Convergence Engineering, 12(4):228-236.

[Kortuem et al., 2010]Kortuem, G., Kawsar, F., Sundramoorthy, V., Fitton, D. (2010). Smart Objects As Building Blocks for the Internet of Things. IEEE Internet Computing, 14(1):44-51.

[Lackovic \& Trunfio, 2014]Lackovic, M., Trunfio, P. (2014). A Service-Oriented Discovery Framework for Cooperating Smart Objects. In Fortino, G., Trunfio, P. (eds), Internet of Things Based on Smart Objects: Technology, Middleware and Applications, Springer, pages 85-105.

[Li et al., 2015]Li, S., Xu, L.D., Zhao, S. (2015). The internet of things: a survey. Information Systems Frontiers, 17(2): 243-259.

[Lopez et al., 2011]López, T.S., Ranasinghe, D.C., Patkai, B., McFarlane, D. (2011). Taxonomy, technology and applications of smart objects. Information Systems Frontiers, 13(2): 281-300.

[Ma et al., 2016]Ma, C., Li, W., Gravina, R., Fortino, G. (2016). Activity recognition and monitoring for smart wheelchair users. In Proc. of the 20th
IEEE International Conference on Computer Supported Cooperative Work in Design (CSCWD), pages 664-669.

[Ma et al., 2005]Ma, J., Yang, L. T., Apduhan, B. O., Huang, R., Barolli, L., Takizawa, M. (2005). Towards a smart world and ubiquitous intelligence: a walkthrough from smart things to smart hyperspaces and UbicKids. International Journal of Pervasive Computing and Communications, 1(1):5368.

[Martins et al., 2013]Martins, L., Lucena, R., Belo, J., Santos, M., Quaresma, C., Jesus, A. P., Vieira, P. (2013). Intelligent Chair Sensor. In Proc. of the International Conference on Engineering Applications of Neural Networks, Springer, pages 182-191.

[Matassa, 2015]Matassa, A. (2015). Interaction with a personalised smart space to enhance people everyday life. In Proc. of CHItaly DC, pages 34-45.

[Matassa \& Simeoni, 2015]Matassa, A., Rossana, S. (2015). Eliciting affordances for smart objects in iot era. In Internet of Things. User-Centric IoT, Springer, pages 77-81.

[McGrew, 2005]McGrew, K. S. (2005). The CattellHorn-Carroll Theory of Cognitive Abilities: Past, Present, and Future.

[Moran, 2005]Moran, T.P. (2005). Unified activity management: Explicitly representing activity in worksupport systems. In Proc. of the ECSCW Workshop on Activity: From Theoretical to a Computational Construct.

[Moran, 1981]Moran, T.P. (1981). The command language grammar: A representation for the user interface of interactive computer systems. International journal of man-machine studies, 15(1):3-50.

[Myerson, 1991]Myerson, R.B. (1991). Game Theory, Analysis of Conflict.

[Mukherjee et al., 2009]Mukherjee, S., Aarts, E., Doyle, T. (2009). Special issue on Ambient Intelligence. Information Systems Frontiers 11(1): 1-5.

[Nardi, 1996]Nardi, B.A. (1996). Context and consciousness: activity theory and human-computer interaction. mit Press.

[Nguyen, 2015]Nguyen, M.A. (2015). Designing Smart Interactions for Smart Objects, page 55. Citeseer.

[Nielsen, 1995]Nielsen, J. (1995). 10 usability heuristics for user interface design. Nielsen Norman Group.

[Norman, 2002]Norman, D. (2002). The psychopathology of everyday things. Foundations of Cognitive Psychology: Core Readings, pages 417.

[Ozkul \& El Zarka, 2013]Ozkul, T., El Zarka A. T. (2013). A New Model for Measuring Human-Smart Machine Interface Quality. Recent Advances in Electrical Engineering Series, (12):191-196. 
[Perez Hernandez \& Reiff-Marganiec, 2014]Hernndez, M. [Vasseur \& Dunkels, 2010]Vasseur, J.P., Dunkels, A. E. P., Reiff-Marganiec, S. (2014). Classifying Smart Objects using Capabilities. In Proc. of the IEEE International Conference on Smart Computing, pages 309-316.

[Russell et al., 2015]Russell, S., Dewey, D., Tegmark, M. (2015). Research Priorities for Robust and Beneficial Artificial Intelligence: an Open Letter. In The Future of AI: Opportunities and Challanges Conference. 2-5 Jan, Puerto Rico.

[Russell et al., 2003]Russell, S., Norvig, P., Intelligence, A. (1995). Artificial intelligence: a modern approach, volume 2. Prentice hall Upper Saddle River.

[Terada \& Tsukamoto, 2005]Terada, T., Tsukamoto, M. (2005). Smart object systems by event-driven rules. In 1st Inter. Workshop on Smart Object Systems, pages 100-109.

[Thorndike, 1920]Thorndike, E.L. (1920). Intelligence and its use. Harper's Mag., 140:227-235.

(2010). Interconnecting smart objects with ip: The next internet. Morgan Kaufmann.

[Wang \& Yu, 2016]Wang, J., Yu, S. (2016). A Comprehensive Theory of Multi-Aspect Interaction with Cyber Physical Systems. International Journal of Smart Home, 10(3):103-118.

[Whitmore et al., 2015]Whitmore, A., Agarwal, A., Da $\mathrm{Xu}, \mathrm{L}$. (2015). The Internet of Things. A survey of topics and trends. Information Systems Frontiers, $17(2): 261-274$.

[Wooldridge, 2009] Wooldridge, M. (2009). An introduction to multiagent systems. John Wiley \& Sons.

[Wooldridge \& Jennings, 1995]Wooldridge, M., Jennings, N. (1995). Intelligent Agents: Theory and Practice. Knowledge Engineering Review, 10:115-152.

[Wu et al., 2014]Wu, Q., Ding, G., Xu, Y., Feng, S., Du, Z., Wang, J., Long, K. (2014). Cognitive Internet of Things: A New Paradigm Beyond Connection. IEEE Internet of Things Journal, 1(2):129-143. 


\section{A Appendix}

Tables 6-9 report the interview tables of this preliminary evaluation.

Table 6 Report table from the interview with Subject 1.1 (design perspective).

\begin{tabular}{|c|c|}
\hline Subject 1.1 & Classification and comment \\
\hline Designed SPO & Smart T-shirt \\
\hline Task & $\begin{array}{l}\text { Monitoring user position when sitting at work and provide feedbacks and alarms about bad } \\
\text { positions }\end{array}$ \\
\hline Knowledge management & $\begin{array}{l}\text { - about itself: NO } \\
\text { - about the user: structural and behavioral (user anatomy and behavior when sitting } \\
\text { - about the context: NO } \\
\text { - about other SPO: NO } \\
\text { - about social relations: NO }\end{array}$ \\
\hline Reasoning & Deductive to decide about feedback and alarms \\
\hline Learning & $\begin{array}{l}\text { Simple forms of caching typical user's behavior, useful to generate feedback about repeated } \\
\text { bad behavior }\end{array}$ \\
\hline Interaction & $\begin{array}{l}\text { HOI: tangible interaction: collecting data from user and physical feedback (task/syntactic } \\
\text { level) } \\
\text { OOI: No interaction }\end{array}$ \\
\hline $\begin{array}{l}\text { Overall comment } \\
\text { (design perspective) }\end{array}$ & $\begin{array}{l}\text { Pros } \\
\text { Using the approach was fairly easy and valuable to understand where I could make choices } \\
\text { and provide insights about improvements on some of the dimensions of analysis. For example, } \\
\text { I could have made better decisions about modeling the context and the user and about adding } \\
\text { more intelligent reasoning capabilities to the T-shirt. } \\
\text { Cons } \\
\text { Nothing specifically. The framework is complex but the graph was very useful to identify } \\
\text { rapidly all the alternatives. }\end{array}$ \\
\hline
\end{tabular}

Table 7 Report table from the interview with Subject 1.2 (design perspective).

\begin{tabular}{|c|c|}
\hline Subject 1.2 & Classification and comment \\
\hline Designed SPO & Smart Bracelet \\
\hline Task & Warn the user about environmental dangers \\
\hline Knowledge management & $\begin{array}{l}\text { - about itself: NO } \\
\text { - about the user: Knowledge about user typical behavior (walking, running) } \\
\text { - about the context: structural knowledge about pollution } \\
\text { - about other SPO: NO } \\
\text { - about social relations: NO }\end{array}$ \\
\hline Reasoning & $\begin{array}{l}\text { Deductive to inform the user about environmental conditions (starting from data collected } \\
\text { by sensors. }\end{array}$ \\
\hline Learning & Simple forms of caching typical user's behavior (when she is used to walk and run) \\
\hline Interaction & $\begin{array}{l}\text { HOI: tangible interaction: Visual feedback to the user (task/syntactic level); messages to } \\
\text { user's smartphone } \\
\text { OOI: No interaction }\end{array}$ \\
\hline $\begin{array}{l}\text { Overall comment } \\
\text { (design perspective) }\end{array}$ & $\begin{array}{l}\text { Pros } \\
\text { At the beginning using the approach was not immediate. However, when I understood the } \\
\text { philosophy of the approach I realized that using it when designing my smart object would have } \\
\text { been interesting, especially for analyzing the requirements. Probably some of the difficulties } \\
\text { I has could have been avoided. Interesting } \\
\text { Cons } \\
\text { As said, it was not immediate using the approach and understanding its philosophy. }\end{array}$ \\
\hline
\end{tabular}

Table 8 Report table from the interview with Subject 2.1 (classification perspective).

\begin{tabular}{|l|l|}
\hline Subject 2.1 & Classification and comment \\
\hline 1st analyzed SPO & Fitness tracker: Fitbit Surge \\
\hline Task & $\begin{array}{l}\text { - Real time tracking (heart rate, activity, exercise, food, sleep, etc.) - tracking progress with } \\
\text { respect to fitness goals - group challenges and contests - automatic recognition of activities } \\
\text { and workouts and real time support for healthy or fitness goals }\end{array}$ \\
\hline
\end{tabular}




\begin{tabular}{|c|c|}
\hline Knowledge management & $\begin{array}{l}\text { - about itself: No structural K; Behavioural K: K about what it has to recommend so that } \\
\text { the user achieves its goals; Teleological K: promoting health behaviours, helping the user to } \\
\text { achieve her goals } \\
\text { - about the user: Real time logs, aggregated data per week, user profile; Type: structural } \\
\text { k about what the user is/has: weight, height, heart rate, elevation, steps, distance, floor, } \\
\text { calories, sleep, nutrition (e.g., food and water logs); Structural K about what the user does: } \\
\text { activity and exercise; Behavioural/Functional K about training programs; Teleological K : } \\
\text { user goals about fitness and activities - about the context: NO - about groups of users: group } \\
\text { modeling: team fitness programs, group logs (group reports) }\end{array}$ \\
\hline Reasoning & $\begin{array}{l}\text { About: user goals, health } \\
\text { How: - automatic activity recognition (of walking, running, aerobic workout, swimming, etc.) } \\
\text { - mapping sensor data (current heart rate, activity, etc.) with health parameters - mapping } \\
\text { sensor data and profile with user goals, e.g. weight goals (getting better calorie burn), optimize } \\
\text { exercise (by exercise recognition, and using real-time heart rate zones throughout workouts) } \\
\text { - mapping sensor data with health parameters, e.g. monitoring health conditions during } \\
\text { exercises, recognizing dangerous or stressful conditions - associating knowledge to alerting } \\
\text { action (e.g., based on heart rate values), to recommend (e.g., managing stress: by relaxing } \\
\text { with guided breathing sessions based on your heart rate) - matching user goals and current } \\
\text { achievements to encourage and stimulate - matching user profile (previous activity, location) } \\
\text { and goals to suggest new trails and new locations - matching performances among users in } \\
\text { groups; } \\
\text { Algorithms: - SmartTrack for automatic activity recognition - Predictive models }\end{array}$ \\
\hline Learning & $\begin{array}{l}\text { About the user: } \\
\text { Structural K (user profile): updates user stats, learns preferences about activities; Functional } \\
\text { K: learns from previous workout the intensity and type for next workout (also rest time } \\
\text { needed), learns from previous workout the user preferences about activities to generate a } \\
\text { custom workout. } \\
\text { How: Fitstar algorithm uses post-workout feedback (most automatically recognized) to per- } \\
\text { sonalize next workout accordingly. }\end{array}$ \\
\hline Interaction & $\begin{array}{l}\text { HOI: tangible interaction and vibration of the tracker for notification; interaction through } \\
\text { smartphone; Interaction level: task level, syntactic level and interaction } \\
\text { OOI: connection with Aria (Wi-Fi smart scale - Measures weight, BMI, lean mass and body } \\
\text { fat percentage); automatic synchronization with smartphone and tablet (no social relation). }\end{array}$ \\
\hline 2nd analyzed SPO & Fitness tracker: Under Armour Band \\
\hline Task & $\begin{array}{l}\text { - Real time tracking (resting, heart rate, workout intensity sleep, steps, etc.) - tracking } \\
\text { progress with respect to fitness, nutrition and sleep goals - alerting and notifications - rec- } \\
\text { ommends how many hours the user should rest/sleep - group challenges }\end{array}$ \\
\hline Knowledge management & $\begin{array}{l}\text { - about itself: NO structural K; Behavioral K: K about what it has to recommend so that } \\
\text { the user achieves its goals; Teleological K: helping the user to achieve her goals } \\
\text { - about the user: Real time logs, aggregated data, user profile; Type: structural k about } \\
\text { what the user is/has: weight, height, heart rate, steps, distance, calories, sleep, nutrition } \\
\text { (e.g., food and water logs), elevation (needs GPS phone data), how the user feels (manually } \\
\text { logged on a } 10 \text { points scale); Structural K about what the user does: activity and exercise. } \\
\text { Behavioural/Functional K about training programs; Teleological K: user goals about fitness } \\
\text { and activities } \\
\text { - about the context: yes, about weather (by integration with IBM Watson) - about others: } \\
\text { NO (not found) }\end{array}$ \\
\hline Reasoning & $\begin{array}{l}\text { About: user goals, health, aimed to provide services as digital coach, workout reminders, etc. } \\
\text { How: most of the reasoning seems to be carried out by IBM Watson (which is, or will be soon, } \\
\text { integrated: UA Record app powered by IBM Watson). They include - clustering personal, } \\
\text { physiological, behavioral and nutrition data to provide recommendations (based also on other } \\
\text { users data) - mapping Watson weather forecasting, Watson news service and geospatial data } \\
\text { to modify fitness program recommendations - automatic recognition of food by using Watson } \\
\text { Visual Recognition and Watson Discovery technology (replacing the manual process of food } \\
\text { logging) - mapping sensor data with health parameters, e.g. monitoring health conditions } \\
\text { during exercises - associating knowledge to generate alerting action (e.g., based on heart } \\
\text { rate values) - matching user goals and current achievements to encourage and stimulate - } \\
\text { matching user profile (previous activity, location) and goals to suggest fitness programs }\end{array}$ \\
\hline Learning & $\begin{array}{l}\text { About the user: } \\
\text { Structural K (user profile): updates user stats, learns preferences about activities; Behavioral } \\
\text { K: learns from previous workout. } \\
\text { How: Watson machine learning and predictive analytics. }\end{array}$ \\
\hline Interaction & $\begin{array}{l}\text { HOI: tangible interaction; good affordances; display that can stay on during workouts, no } \\
\text { need to push buttons; multi-colored light for notification; interaction through smartphone } \\
\text { and UA Record app; Interaction level: task, syntactic and interaction } \\
\text { OOI: Interactions among the UA band, smart scale and heart rate strap (together are named } \\
\text { UA Health Box); Interaction with UA smart shoes (for more precise tracking); automatic } \\
\text { synchronization with smartphone and tablet. }\end{array}$ \\
\hline
\end{tabular}




\begin{tabular}{|l|l|}
\hline Overall comment & Pros \\
(classification perspective) & The framework is very useful to make you analyze an object in depth and compare it with \\
& other objects. It forces you to analyze everything in detail. \\
& Cons \\
& I had some difficulties distinguishing between behavioral and functional K. For this reason \\
& in my classification I often considered them together. However, this distinction becomes \\
& meaningful when designing an object since it makes you distinguish methods from techniques. \\
\hline
\end{tabular}

Table 9 Report table from the interview with Subject 2.2 (classification perspective).

\begin{tabular}{|c|c|}
\hline Subject 2.2 & Classification and comment \\
\hline 1st analyzed SPO & Fitness tracker: Fitbit Surge \\
\hline Task & $\begin{array}{l}\text { - It tracks real time activities and health parameters } \\
\text { - It provides alerts and notifications } \\
\text { - It provides feedback for nutrition and activities }\end{array}$ \\
\hline Knowledge management & $\begin{array}{l}\text { - about itself: not sure } \\
\text { - about the user: logs about the user activities and nutrition; per week statistics; Type: } \\
\text { structural k: yes, Behavioral K: yes about activities, Functional K: NO, Teleological K: yes } \\
\text { about user goals; } \\
\text { - about the context: NO } \\
\text { - about others: limited }\end{array}$ \\
\hline Reasoning & $\begin{array}{l}\text { About: best activities and programs for the user; } \\
\text { How: several techniques and methods, probably comparing results with other users; - rea- } \\
\text { soning about distance between user goals and current progress - generation of exercises - } \\
\text { suggestions about calories and ways to burn them - personalized workouts }\end{array}$ \\
\hline Learning & $\begin{array}{l}\text { Yes, it learns by using Fitstar algorithm from post-workout data; } \\
\text { it learns about the user preferences and intensity of activities }\end{array}$ \\
\hline Interaction & $\begin{array}{l}\text { HOI: tangible; alerts and notifications by using vibration and visual cues on the bracelets; } \\
\text { Fitbit App for everything else } \\
\text { OOI: not found apart synchronizing with smartphone and tablet. }\end{array}$ \\
\hline 2nd analyzed SPO & Fitness tracker: Under Armour Band \\
\hline Task & $\begin{array}{l}\text { - It tracks real time activities and health parameters } \\
\text { - It provides alerts and notifications } \\
\text { - It provides feedback for nutrition and activities - It provide suggestions about timing for } \\
\text { exercises, optimal sleep time, etc. }\end{array}$ \\
\hline Knowledge management & $\begin{array}{l}\text { - about itself: not sure } \\
\text { - about the user: statistics about the user activities and feeling; Type: structural k: yes, } \\
\text { Behavioral K: yes about activities, Functional K: NO, Teleological K: yes about user goals } \\
\text { and wellness; } \\
\text { - about the context: yes, including weather, location, etc. } \\
\text { - about others: yes, used in learning algorithms. }\end{array}$ \\
\hline Reasoning & $\begin{array}{l}\text { About: best activities and programs for the user; } \\
\text { How: not specified in detail. It exploits IBM Watson reasoning algorithms, probably com- } \\
\text { paring results with other users; - reasoning about timing for exercises, also based on context } \\
\text { conditions - suggestions about calories and way to burn them, rest, sleep, etc. }\end{array}$ \\
\hline Learning & $\begin{array}{l}\text { Yes, it learns by using IBM Watson algorithms; } \\
\text { it learns about the user progresses as concerns exercises and weight. }\end{array}$ \\
\hline Interaction & $\begin{array}{l}\text { HOI: tangible; alerts and notifications by visual cues on the bracelets; UA Record app for } \\
\text { everything else } \\
\text { OOI: UA band can be connected with UA scale and chest strap; synchronization with smart- } \\
\text { phone and tablet. }\end{array}$ \\
\hline $\begin{array}{l}\text { Overall comment } \\
\text { (classification perspective) }\end{array}$ & $\begin{array}{l}\text { Pros } \\
\text { A useful guideline to compare smart objects. It can help when you want to make a systematic } \\
\text { comparison. Given that the framework provides a guideline, it speeds up the definition of } \\
\text { criteria to compare objects. } \\
\text { Cons } \\
\text { It often happens that you cannot find all the information you need about the object you are } \\
\text { analyzing, therefore the comparison has to be done at a higher level. }\end{array}$ \\
\hline
\end{tabular}

